\title{
Principles of Mushroom Developmental Biology
}

\section{David Moore}

Faculty of Life Sciences, The University of Manchester, Manchester, UK

Address all correspondence to D. Moore, Faculty of Life Sciences, The University of Manchester, 1.800 Stopford Building, Oxford Road, Manchester M13 9PT, UK; david.moore@manchester.ac.uk

\begin{abstract}
Research done over the last century has persistently indicated major differences between fungi, animals, and plants. Unfortunately, for most of that time fungi have been considered, quite erroneously, to be closely related to plants; as observations have been constrained to comply with this fundamental error, a proper appreciation of fungal developmental biology has been seriously inhibited. During the final quarter of the $20^{\text {th }}$ century, the phylogenetic status of the true fungi as an independent Kingdom of eukaryotes became clear. In this review, I bring together some of the observations, old and recent, that contribute to our current understanding of the way that fungi construct multicellular structures.
\end{abstract}

KEYWORDS: morphogenesis, fungi, tissues, fruit bodies, cell interactions, morphogens, differentiation, regulation

\section{INTRODUCTION}

Development is formally defined as the process of change and growth within an organism during the transition from embryo to adult. This definition immediately illustrates a major challenge faced by any mycologist interested in development, which is the specification of "embryo"-reflecting the fact that most developmental biologists deal with animal systems. The challenge occurs because the concepts and vocabulary of development derive mostly from animal embryology and reflect the interactive behavior of animal cells. Plants have made some contribution to theoretical developmental biology, which is fitting for organisms with cell biology so different from that of animals, but there is no parallel representation of fungal development. This is an unfortunate deficiency, given that fungi differ so much from both animals and plants.

I should stress that I am referring specifically to the poor contribution made by studies of multicellular development in fungi (the true analogue of animal embryology). There is an irony in the fact that so much of what we know about eukaryotic molecular cell biology, cell structure, and the cell cycle derives from work with yeast. In many ways this creates a false sense of satisfaction for mycologists, but very little of this knowledge has a real bearing on fungal morphogenesis, even though those interested in the yeast/filamentous transition, in particular, use the word and write confidently about hyphal "morphogenesis" (Harris et al., 1999; Gancedo, 2001; Mösch, 2002; Warenda and Konopka, 2002; Seiler and Plamann, 2003).

This verges on being a misnomer for the reason that what they describe would be called cell differentiation in any other organism. The word morphogenesis is generally used to encompass the development of the body form of a multicellular animal or plant (fungi do not feature in such definitions!). The key

\section{ABBREVIATIONS}

GUI: graphical user interface; PCD: programmed cell death 
problems in morphogenesis have always related to the interactions between cells from which the patternings of cell populations arise and from which the morphology of the embryo emerges.

Regrettably, it is still often necessary to remind people that fungi are not plants. Indeed, this simple biological fact is not explicitly included in any of the curriculum specifications used now, in 2004-2005, as the basis for teaching science to students up to the age of 16 in schools in the United Kingdom. Consequently, there are a great many people, young and old alike, who, if they ever do think about it at all, will be firmly convinced that fungi are plants. Peculiar plants, perhaps, but plants nevertheless. This notion, of course, is completely wrong.

\section{KINGDOM FUNGI}

Plants, animals, and fungi should now be clearly understood to form three quite distinct Kingdoms of eukaryotic organisms (Whitaker, 1969; Margulis, 1974, 1992; Cavalier-Smith, 1981, 1987, 2002; Margulis and Schwartz, 1982). This arrangement is reflected in current ideas about the early evolution of eukaryotes, in which the major Kingdoms are thought to have separated at some protistan level (Moore, 1998, Chap. 1; Feofilova, 2001; Margulis, 2004).

A major aspect of the original definition of the Kingdoms (Whitaker, 1969) was their means of nutrition (plants use radiant energy, animals engulf food particles, fungi absorb digestive products), and this apparently simple basis for separation embraces numerous correlated differences in structure and life style strategy. Other noncorrelated differences also emerge, and among these is the way in which multicellular architectures can be organized. Even in lower animals, a key feature of embryo development is the movement of cells and cell populations (Duband et al., 1986; Blelloch et al., 1999); evidently, cell migration (and everything that controls it) plays a central role in animal morphogenesis. Being encased in walls, plant cells have little scope for movement, and their changes in shape and form are provided for by control of the orientation and position of the mitotic division spindle and, consequently, the orientation and position of the daughter cell wall, which forms at the spindle equator (Gallagher and Smith, 1997).

Fungal cells are also encased in walls, of course; but their basic structural unit, the hypha, has two peculiarities requiring that fungal morphogenesis be totally different from plant morphogenesis. These are that a hypha grows only at its apex (BartnickiGarcia, 2002; Momany, 2002), and that cross walls form only at right angles to the long axis of the hypha (Harris, 2001). The consequence of these features is that no amount of cross wall formation (cell division) in fungi will turn one hypha into two hyphae (Field et al., 1999; Howard and Gow, 2001; Momany, 2001; Momany et al., 2001). The fundamentally crucial understanding that shows fungal developmental morphogenesis to be distinct from both animals and plants is that fungal morphogenesis depends on the placement of hyphal branches. To proliferate, a hypha must branch; and to form the organized structure of a tissue, the position at which the branch emerges and its direction of growth must be controlled.

\section{Origin of Kingdom Fungi}

Arranging organisms into kingdoms is a matter of systematics; an agreed-upon scheme of categorizing the estimated 13-14 million species currently thought to be alive on this planet. Yet the threeKingdoms arrangement of animals, fungi, and plants is a natural classification that reflects the current thinking about the early evolution of eukaryotes (Margulis, 2004). This is an interesting story that bears repetition, if only to provide some context for the discussion that follows. The solar system formed about $4.5 \times 10^{9}$ years ago. There are microbial fossils in terrestrial rocks that are $3.5 \times 10^{9}$ years old. Life might have evolved even before that time, but calculations based on study of craters on the Moon suggest that the Earth/Moon system was subjected to gigantic asteroid impacts up to about $3.8 \times 10^{9}$ years ago. These impacts were sufficiently massive to release enough energy to heat-sterilize the Earth's surface. Any life that had evolved in those more distant times would have been destroyed by the next impact. 
Once these cataclysmic impacts stopped and the Earth's surface stabilized sufficiently for life to evolve, the first bacteria-like fossils would have been laid down (Knoll, 2003). After this, there was a period of $1.5 \times 10^{9}$ years during which early bacteria continued to evolve before the higher organisms emerged. Eukaryotes and eubacteria last shared a common ancestor about $2 \times 10^{9}$ years ago (Knoll, 1992; Gupta and Golding, 1996). In the present day about 60 lineages of eukaryotes can be distinguished on the basis of cellular organization (Patterson, 1999). Most of these are traditionally classified as protists, but one lineage comprises green algae and plants and two others animals and fungi, and these three major eukaryotic kingdoms diverged from one another about $1 \times 10^{9}$ years after the appearance of the eukaryotic cell (Knoll, 1992; Philippe et al., 2000).

Our understanding of eukaryote phylogenetic relationships is not yet complete (Knoll, 1992; Cavalier-Smith, 1993; Kuma et al., 1995; Kumar and Rzhetsky, 1996; Sogin et al., 1996; Katz, 1998; Sogin and Silberman, 1998; Katz, 1999; Roger, 1999). Recent discussion has stressed the importance of the symbiotic partnership between phototrophs and fungi in early colonization of the land, protein sequence comparisons indicating that major fungal and algal lineages were present one billion years ago (Heckman et al., 2001). Animals and fungi are more directly related, however. It is generally agreed that the Metazoa and choanoflagellates (collar-flagellates) are sister groups, and that these, together with the fungi and chytrids, form a single lineage called the opisthokonts. This name opisthokont (Copeland, 1956) refers to the posterior (opistho) location of the flagellum (kont) in swimming cells. The term was applied to the (animals + fungi) clade (Cavalier-Smith and Chao, 1995) because comparative molecular analysis has indicated that fungi and animals are each other's closest relatives (Baldauf and Palmer, 1993; Wainright et al., 1993; Sogin and Silberman, 1998; Baldauf, 1999; Patterson and Sogin, 2000).

So it seems that plants diverged first, and the progression that emerges is that plants arose from the common eukaryotic ancestor $1 \times 10^{9}$ years ago, then a joint fungal/animal line continued for another 200 million years until that lineage diverged 800 million years ago (Berbee and Taylor, 1993; Doolittle et al., 1996; Sugiyama, 1998; Berbee and Taylor, 1999).

Recognizable fungi must have been around as long ago as that, because from rocks only a few hundred million years younger-about 570 million years old-there is evidence in the form of fossil spores for all the major groups of fungi that exist today (Pirozynski, 1976a,b; Kalgutkar and Sigler, 1995). And it is quite clear that fungi were crucially important in the shaping of ancient ecosystems. The oldest fossils found to date (which are about 650 million years old) have been suggested to be lichens rather than worms or jellyfish (Retallack, 1994).

Although this is a hotly disputed interpretation, intimate associations between fungi and plants occurred very early in evolution (Pirozynski, 1981). Almost all land plants of today form cooperative mycorrhizal associations with fungi, which contribute to the mineral nutrition of the plant and can benefit plants in a variety of other ways. This cooperation would have eased, if not solved, some of the most difficult problems the first land plants faced as they emerged from the primeval oceans. Some of the oldest (about 400 million year old) plant fossils contain mycorrhizal structures almost identical to those that can be seen today (Harvey et al., 1969; Wright, 1985; Hass et al., 1994; Taylor et al., 1995; Heckman et al., 2001). It is now generally thought that the initial exploitation of dry land by plants about 430 million years ago depended on the establishment of cooperative associations between fungi and algae on the one hand (as lichens), and between fungi and emerging higher plants (forming mycorrhizas) on the other.

An even more radical interpretation is that the oldest terrestrial fossils were actually saprotrophic fungi. The oldest terrestrial fossils we have are made up of masses of thread-like and tube-like structures. They are called nematophytes, the name being derived from the Greek nema, which means thread, combined with phyte because of the belief when they were originally found that they were plants in origin. Nematophyte fossils started in rocks more than 450 million years old, and, in terms of both abundance and diversity, they were important components of the Earth's terrestrial ecosystems for the best part 
of 100 million years, from the Ordovician to the early Devonian geological periods. They included by far the largest organisms in early terrestrial ecosystems; some specimens of a nematophyte genus called Prototaxites have been reported to be over one meter wide and to reach heights of 2-9 meters. These fossils are now being reinterpreted, following developments in chemical analysis that suggest that their walls were not composed of the sorts of chemicals you would expect in plant cell walls. As a result, it has been claimed that some of the nematophytes (including Prototaxites) were terrestrial fungi or lichens, creating the possibility that the earliest terrestrial organisms were fungal, some being far larger than any known today (Gray, 1985; Wellman, 1995; Selosse and Le Tacon, 1998; Wellman and Gray, 2000; Hueber, 2001; Selosse, 2002; Southwood, 2003).

\section{Origins of Developmental Biology}

Whatever the nature of these extremely early organisms, it is evident that the major kingdoms separated from one another at some unicellular level of organization. This being the case, it follows that plants, animals, and fungi became distinct from one another long before the multicellular grade of organization was established in any of them. They will, of course, share all those features that clearly categorize them as eukaryotes, but there is no logical reason to expect that these three Kingdoms will share any aspect of their multicellular developmental biology. If evolutionary separation between the major Kingdoms occurred at a stage prior to the multicellular grade of organization, then these Kingdoms must have "learned" how to organize populations of cells independently. The fungal hypha differs in so many important respects from animal and plant cells that significant differences in the way cells interact in the construction of organized tissues must be expected.

Inevitably, in many cases these very different organisms needed to solve the same sorts of morphogenetic control problems and may have found some common strategies. Comparison of the way similar functions are controlled can reveal whether and how different cellular mechanisms have been used to solve common developmental demands (Meyerowitz, 1999), although, of course, fungi are not discussed. However, there are now sufficient filamentous fungal genomes in the public sequence databases to warrant direct sequence comparisons with animal and plant genomes, and a recent search of filamentous fungal genomes with gene sequences generally considered to be essential and highly conserved components of normal development in animals failed to reveal any homologies (Moore et al., 2005).

\section{Data Mining Fungal Genomes}

This initial survey attempted to establish whether fungal multicellular development shows any closer relationship to that of animals than to that of plants by searching filamentous fungal genomic databases for sequences demonstrating similarity to developmental gene sequences. The phylogenetic logic of this approach is that it is not unreasonable to argue that the opisthokonts evolved basic strategies for dealing with cellular interactions prior to their divergence, and that evidence of this might be found in present day genomes in the form of similarities between sequences devoted to tasks that can be defined broadly as "developmental." This survey concentrated on cell/cell signaling because it is essential for many morphogenetic processes ranging from developmental patterning to the regulation of cell proliferation and cell death.

Sequences of the animal signaling mechanisms Wnt, Hedgehog, Notch, and TGF- $\beta$ were used to search the Basidiomycetes Coprinus cinereus (syn. Coprinopsis, Redhead et al., 2001) and Ustilago maydis (Anon, 2003a,b) at the Whitehead Institute's Centre for Genome Research; Cryptococcus neoformans (update of 29/4/03) at TIGR; Phanerochaete chrysosporium at the Department of Energy's (DOE) Joint Genome Institute; and the ascomycetes Aspergillus nidulans (Anon, 2003c) and Neurospora crassa (Galagan et al., 2003), also at the Whitehead Institute's Centre for Genome Research; and Aspergillus fumigatus at TIGR. These form a representative and accessible collection of tissue-making ascomycete and basidiomycete filamentous fungal genomic 
databases that are finished or nearing completion. These genomes were searched for homologues of Caenorhabditis elegans sequences involved in the signaling mechanisms Notch, TGF- $\beta$, Wnt (including the MOM and POP genes), and also a Hedgehog sequence from Drosophila melanogaster (as C. elegans lacks a Hedgehog homologue), but all were found to be absent from the seven query fungi, just as they are absent from plants (Moore et al., 2005).

Plants have their own highly developed signaling pathways, one of which is the ethylene perception and signal transduction system, which is carried out by a family of membrane-bound receptors of which ETR1 and ESR1 are members (Muller-Dieckmann et al., 1999; Zhao et al., 2002; Stearns and Glick, 2003). Again, however, no substantive similarities were returned by a search of fungal genomes using the Arabidopsis thaliana ETR1 and ESR1 sequences, suggesting that fungi also lack anything related to the plant hormone ethylene-signaling pathway (Moore et al., 2005).

Lack of homologies leads to the conclusion that fungal and animal lineages diverged from their common opisthokont line well before the emergence of any multicellular arrangement, and that the unique cell biology of filamentous fungi has caused control of multicellular development in fungi to evolve in a radically different fashion from that in animals and plants. I must emphasize that this was an initial survey. The conclusion must be moderated by the recognition that the sequence databases are not yet comprehensive. The fact that $41 \%$ of the predicted proteins of the Neurospora crassa genome have been shown to lack significant matches to known proteins from public databases (Galagan et al., 2003) indicates that the database deficiencies are not minor.

Nevertheless, we have embarked upon what we intend to be a fully comprehensive data-mining exercise using Internet web robots (Meškauskas, 2005). Preliminary results indicate that of 547 polypeptide sequences assigned to the category "development" (defined as biological processes specifically aimed at the progression of an organism over time from an initial condition-e.g., a zygote, or a young adult - to a later condition-e.g., a multicellular animal or an aged adult-only 37 sequences are shared among all three kingdoms, 14 are shared only between fungi and animals, two sequences are shared between plants and fungi, and one sequence was fungus specific (Meškauskas, personal communication). These observations contribute to the idea that fungi have more affinity with the animal kingdom than with the plants.

We plan to extend the comprehensive search into DNA genome databases. However, it must be appreciated that the scales of some of the differences reflect the relative amounts of research done with the three kingdoms. It will be many years before the library of available genomes is sufficiently representative for the sort of survey described above to be truly complete. Until we achieve this, we have to proceed with the incompletely supported proposition that molecular control of fungal developmental biology is fundamentally different from that of animals or plants, and enquire into the rules that may apply. I will start consideration of this aspect by describing a recent mathematical model of hyphal growth, called the Neighbour-Sensing model, and a Java ${ }^{\mathrm{TM}}$ computer program realization of it that together generate extremely realistic visualizations of filamentous hyphal growth (Meškauskas et al., 2004a,b).

\section{Computer Simulations with Cyberfungi}

The Neighbour-Sensing model brings together the basic essentials of hyphal growth kinetics into a vector-based mathematical model in which the growth vector of each virtual hyphal tip is calculated at each iteration of the algorithm by reference to the surrounding virtual mycelium. Kinetic hyphal growth equations relate hyphal length, number of branches, and growth rate, and incorporation of the influence of external factors on the direction of hyphal growth and branching (i.e., tropisms) provides us with a cyberfungus that can be used for experimentation on the theoretical rules governing hyphal patterning.

The Neighbour-Sensing model employs a variety of tropisms by incorporating mathematical representations of the nature of the signal, its propagation through the medium, and its attenuation; the mathematical model deals with these as abstractions.

In the Neighbour-Sensing program, each hyphal 
tip is an active agent, described by its $3 \mathrm{D}$ position, length, and growth vector, that is allowed to vector within 3D data space using rules of exploration that are set (initially by the experimenter) within the program. Those Neighbour-Sensing rules are the biological characteristics. They start with the basic kinetics of in vivo hyphal growth, include branching characteristics (frequency, angle, position), and, through the tropic field settings, involve interaction with the environment. A graphical user interface (GUI) written into the $\mathrm{Java}^{\mathrm{TM}}$ realization of the Neighbour-Sensing model makes adjustment of the parameters an easy operation for even the casual user of the program, but the experimenter does not define the geometrical form of the outcome of a Neighbour-Sensing program run-it is not a painting program. Rather, the final geometry must be reached by adapting the biological characteristics of the active agents during the course of their growth-exactly as in life.

The program starts out with just one hyphal tip, which is equivalent to the fungal spore. Each time the program runs through its algorithm, the tip advances by a growth vector (initially set by the user) and may branch (with an initial probability set by the user). The Neighbour-Sensing model "grows" a simulated mycelium in the computer using branching rules decided by the user and calculates everything else it needs to generate a mycelium. As the cyberhyphal tips grow out into the modeling space, the model tracks where they've been, and those tracks become the hyphal threads of the cybermycelium. These simple features (or parameters), in which direction of growth is random, are sufficient to result in a spherical colony (circular if growth is restricted to a flat plane). So the first conclusion of the modeling experiments is that the characteristically circular colony of fungi does not need to be contrived; it is a natural outcome of the exploratory apical growth of fungi.

Real fungi, however, do not grow in random directions. Real hyphal tips grow in accordance with their reactions to the effects of one or more tropisms. In this mathematical model of hyphal growth, the growth vector of each virtual hyphal tip depends upon values derived from its surrounding virtual mycelium. Effectively, the mathematics allows the virtual hyphal tip to sense the neighbouring mycelium, which is why it is called the NeighbourSensing model. Tropisms are implemented using the concept of a field to which growing hyphal tips react. In the real physical world, the field might be an electrical field for a galvanotropism, the Earth's gravitational field for a gravitropism, or a chemical diffusion gradient for a chemotropism. In the mathematical model, the same basic field equations can be used for all, the different tropisms being distinguished by the different physical characteristics ascribed to the field.

The published model features seven tropisms: (1) negative autotropism, based on the hyphal density field; (2) secondary long-range autotropism (that attenuates with either direct or inverse proportionality to the square root of distance); (3) tertiary longrange autotropism, which attenuates as rapidly as the negative autotropism but can be given a large impact value; (4) and (5) two galvanotropisms based on the physics of an electric field produced by the hypha that is parallel to the hyphal long axis; (6) a gravitropism, which orients hyphae relative to the vertical axis of the user's monitor screen; and (7) a horizontal plane tropism, which provides a way of simulating colonies growing in or on a substratum such as agar or soil by imposing a horizontal geometrical constraint on the data space the cyberhyphal tips can explore. The user can determine how strongly the hyphal tips are limited to the horizontal plane and the permissible layer thickness.

These features form the parameters of the model, and all are under the control of the user via the GUI. The Neighbour-Sensing model provides the user with a set of abstract mathematical tools that amount to a culture of a newly arrived fungus. The rate of growth of the cyberfungus is user decided, depending only on the power of the user's computer. It is possible to do more experiments in an afternoon's computing than can be done in a year in the laboratory.

The Neighbour-Sensing model has been used in a series of experiments (Meškauskas et al.,2004b) to show that complex fungal fruit body shapes can be simulated by applying the same regulatory functions to all of the growth points active in a structure at any specific time- the shape of the fruit body emerges 
as the entire population of hyphal tips respond together, in the same way, to the same signals.

The significant observation here is that no global control of fruit body geometry is necessary, so the important phrase in the previous sentence is that "the shape of the fruit body emerges."This is entirely an outcome of the apical growth pattern of fungal hyphae. All of the parameter sets that generate shapes reminiscent of fungal fruit bodies feature an organized series of changes in parameter settings applied to all of the hyphal tips in the simulation. In the real biological system, such morphogenetic programs could be based on internal clocks of some sort that synchronize behavior across a developing structure on the basis of time elapsed since some initiating event.

These computer simulations demonstrate that because of the kinetics of hyphal tip growth, very little regulation is required to generate fungal fruit body structures. Our next challenge is to establish whether observations of living fungi can provide guidance about the biological processes that might be involved.

\section{Observations of Real Fungi}

The first important point to make is that fungi are modular organisms, like clonal corals and vegetatively propagated plants, in which growth is repetitive and a single individual will have localized regions at very different stages of development (Harper et al., 1986; Andrews, 1995). The general developmental rules may be applicable to all multicellular structures (indeed, that is the basis on which the comparison is made), but it is important to keep this fundamental nature of the organisms in mind when attempting to apply the principles of pattern formation and morphogenesis derived from animal models, where the embryos are individual whole organisms rather than fruit bodies.

It is also essential to emphasize that most research concerning observations on fungal anatomy and development has been done in order to clarify taxonomic differences (Watling and Moore, 1994; Clémençon, 1997, 2004). This has been necessary because fungal classification has been based on the shape and form of the spore-producing tissue- the hymenium - and on the hymenophore- the structure on which the hymenium was borne-since the classification was first developed at the beginning of the $19^{\text {th }}$ century (Persoon, 1801; Fries, 1821). Shape was not a factor in driving plant or animal classification during the $20^{\text {th }}$ century, but it remained dominant in fungal classification until the last quarter of the $20^{\text {th }}$ century. The traditional classification scheme is now being challenged by use of molecular methods to establish relationships and, it must be said, by more detailed microscopical analyses started by Reijnders $(1948,1963)$ and now hugely contributed to by Clémençon (2004).

The traditional classification scheme is the one that most of us know. We know about agarics that have gills (vertical plates) beneath an umbrellashaped cap (pileus), as in the ordinary cultivated mushroom. But it has emerged that this single group is actually a collection of organisms with very diverse evolutionary origins. The feature that unites them (the fact that their spore forming tissues are amplified by being distributed over the plate-like gills) is one to which there are several evolutionary and developmental routes.

The function of the mushroom fruit body (basidiome) is to produce as many basidiospores as the structure will allow. Reijnders' $(1948,1963)$ careful observation of developing basidiomes revealed that there are at least ten ways by which the familiar mushroom shape can be formed, a shape that is excellently designed to give protection to the developing hymenia in exposed environments (Watling and Moore, 1994). These vary from those with naked development, which includes the majority of the bracket fungi developing from a concentration of tightly bound hyphae forming a rounded structure (known to foresters as a conk) to those with a complete enclosing membrane or membranes that only break just before maturity. Importantly, relationships between species based on the type of development conform to classification schemes based on other features (Reijnders and Stalpers, 1992; Watling and Moore, 1994).

The veils formed by agarics are considered to be protective; they allow the hymenia to develop in a sheltered environment that is controlled by the 
organism itself. The shape of the gills is strongly tied to the constraints of this environment within the developing basidiome and has led to the use in identification of gill attachment, which is how the gill is attached to the stem (stipe) apex. At least eight types of attachment have been used and are now undergoing analytical examination (Pöder, 1992).

There is a large group of fungi that have their basidiospores enclosed in the basidiome, even when mature. They are generally called Gasteromycetes and include puffballs, earthstars, and earth-balls, all adapted into the form of an epigeous or hypogeous sack of spores. Basidiomycetous hypogeous fungi, as with their ascomycete cousins the truffles, have a distinctive odor to attract animals to excavate the buried fruit body and distribute spores while eating it. Indeed, hypogeous fungi form a major proportion of the nutrition of many small mammals and consequently make a crucial contribution to food webs in nature (an example is described by Molina et al.,2001). The stinkhorns are also included alongside the gasteromycetes. These parallel the agarics in gross morphology, although their hymenium is adapted for insect dispersal as opposed to wind dispersal, and they also produce penetrating odors to attract insects. The shape of the stinkhorns is highly specialized, with similarities to the bizarre shapes and strong smells of insect-attracting flowering plants.

The similarities in shapes found in these groups are again, as in the agarics, derived from convergent evolution from several different ancestral positions. The similarity in shape and ecological function does not signify unity of relationship; rather, it represents an evolutionary goal at which diverse lineages have arrived (Reijnders, 2000).

A similar conclusion is reached when the detailed cellular structure involved in growth to maturity is considered. Fruit body structure can be expanded in several ways to optimize spore production. For example, in the Russulales, this is achieved as columns and rosettes of hyphae expanding in an orchestrated way are accompanied in Coprinus (= Coprinopsis) by narrow, uninflated hyphae (Reijnders, 1976; Hammad et al., 1993a,b). In their distribution these narrow hyphae resemble the inducer hyphae of Russula and Lactarius (Reijnders, 1976; Watling and Nicoll, 1980). In the Amanitas, the mode of gill formation is unusual (being schizohymenial), and this difference correlates with the unusual way that individual cells of hyphae of the flesh undergo massive inflation to cause the fruit body to expand (Bas, 1969).

This description of tissue construction in mushrooms and toadstools, called hyphal analysis, was introduced by Corner (1932a,b, 1966) (Redhead, 1987; Ryvarden, 1992). Hyphal analysis is entirely descriptive, and the only quantitative study published is that done by Hammad et al. (1993a,b), who showed that enumerating cell types at different stages of development (in the fruit bodies of Coprinopsis cinereus) is a powerful way of revealing how fruit body structure emerges during morphogenesis as a result of changes in hyphal type and distribution. Previous to this study, mushroom structure has been measured in terms of fruit body height, cap diameter, and diameter of the stem.

Ingold (1946) and Bond (1952) used published illustrations of a wide range of agarics to extract graphical relationships between these features, arriving at the conclusion that smaller fruit bodies have proportionately longer and more slender stems. Watling (1975) established a different graphical representation for the Bolbitiaceae, using measurements from fresh specimens. He pointed out faults with the earlier work, which depended on selective use of published collections of illustrations.

We should be wary of generalizations from combined measurements of different species. But morphological measurements are valuable and have practical value. They have been used to define the "normal" mushroom for the Agaricus bisporus crop (Flegg, 1996), and image analysis of shape, form, and color of $A$. bisporus can be related statistically to crop development (van Loon et al., 1995). The practical value of such approaches is that they contribute to the design of control methods for machine automation of crop picking.

From the conceptual point of view, measuring and counting cells in different regions of fruit bodies at different stages of development reveals specific patterns of cell differentiation (particularly inflation), which mechanically generate the final form 
of the fruit body. A common feature that emerges is that in most fungal tissues there is a repetitive substructure comprising a central hypha (which remains hyphal) and an immediately surrounding family of hyphae that differentiate in concert. These hyphal aggregations were identified and termed byphal knots by Reijnders $(1977,1993)$. The indications are that the central hypha induces the differentiation of its surrounding family. If this is the case, then any control exerted by morphogens must be imposed on the central induction hypha that may not differentiate itself, but simply relay the message to its dependent family. This two-stage process may influence the physical characteristics of the morphogen(s), but it might also influence their number. If the induction hyphae determine the terminal differentiation of their surrounding family, the morphogen(s) may simply need to instruct a differentiation process to occur, without defining the nature of that differentiation. The latter might be determined by local environmental, physical, or nutritional factors.

The patterns revealed show that positional information is regulated in time and space and strongly suggest that patterning in fungal tissues is organized by signaling molecules. Attempts to determine the nature of the signals used in fungi have been initiated (Novak Frazer, 1996); oddly enough, with very few exceptions, compounds detected on the basis of morphogenetic bioassays prove to be unexceptional components of normal intermediary metabolism when purified. It is a moot point whether this experience indicates that fungi actually make use of metabolic intermediates as morphogens, or whether fungal morphogens are so exquisitely sensitive that they are lost during all the purification procedures so far attempted.

\section{Plasticity in Form}

Clearly, fungal systematists are now appreciating that fruit body shape should not hold the central position it once did. One reason it is less useful is that it is proving to be a more flexible character than previously thought. Variation in basidiomycete fruit body morphology in response to environmental change is easily demonstrated. Bondartseva (1963) was the first to warn against placing too much taxonomic emphasis on a single character for this reason. In fact, plasticity in the shape and form of fruit bodies arising on a particular strain can be caused by a variety of events.

Many morphological mutants or genetic variants have been induced or isolated from nature, especially in Coprinus (= Coprinopsis) cinereus and Schizopbyllum commune (Raper and Krongelb, 1958; Takemaru and Kamada, 1972; Kanda and Ishikawa, 1986; Kanda et al., 1989). Such mutants can be used to establish developmental pathways (Esser et al., 1977; Moore, 1981) and to make detailed studies of particular phenotypes (Kamada and Takemaru, 1977a,b; Kanda et al., 1990; Boulianne et al., 2000; Lu et al., 2003). Fruiting is a complex multigene process in these fungi (De Groot et al., 1997), which is further modulated by environmental factors (Leslie and Leonard, 1979, 1984; Manachère et al., 1983; Meinhardt and Esser, 1983; Prillinger and Six, 1983; Raudaskoski and Salonen, 1984; Manachère, 1985, 1988; Leatham and Stahmann, 1987; Moore, 1998; Kües, 2000; Kües and Liu, 2000; Kües et al., 2002; Han et al., 2003; Sánchez, 2004).

There is some evidence for genetic mosaics in Armillaria fruit bodies (Peabody et al., 2000), for genetically different multiple initiation pathways (Leslie and Leonard, 1979) and, conversely, for different structures (specifically sclerotia and basidiomes) sharing a common initiation pathway (Moore, 1981). Fruiting in haploid, primary homothallic species, such as Volvariella bombycina and V. volvacea (Chang and Yau, 1971; Chiu and Chang, 1987; Royse et al., 1987) and in homokaryons in heterothallic species (Uno and Ishikawa, 1971; Elliott, 1972,1985; Stahl and Esser, 1976; Dickhardt, 1983; Graham, 1985) shows that fruiting is independent of the sexual cycle regulated by the incompatibility system in heterothallic species (Kües and Casselton, 1992; Kronstad and Staben, 1997; Casselton and Olesnicky, 1998; Kües et al., 1998; Chiu and Moore, 1999; Kües and Liu, 2000; Brown and Casselton, 2001; Kothe, 2002). Basidiome variants must be interpreted against this background of quite diverse genetic control mechanisms. 


\section{Epigenetic Plasticity}

Epigenetic plasticity is possibly more interesting from the developmental point of view. These are instances where, for some reason, the development of a normal genotype is disturbed, but without change to that genotype (Steimer et al., 2004).

This sort of plasticity in fruiting morphogenesis may be a strategy for adaptation to environmental stress. The rose-comb disease of the cultivated mushroom, Agaricus bisporus, in which convoluted growths of hymenium develop over the outer surface of the cap, seems to be caused by mineral oil volatiles in mushroom farms (Lambert, 1930; Flegg, 1983; Flegg and Wood, 1985). Viral infections have been implicated in some instances-e.g., in Laccaria, $A r-$ millaria, and Inocybe (Blattny et al., 1971,1973), and fungal attack in others. For example, Buller (1922) showed that gill-less fruit bodies of Lactarius piperatus were caused by parasitism by Hypomyces lactifluorum, and Watling (1974) showed that primordia of Entoloma abortivum can be converted to a puff-ball structure by interaction with Armillaria mellea.

Fruit body polymorphism or developmental plasticity like this has been reported in various fungal species (Buller, 1922, 1924; Keyworth, 1942; Singer, 1975; van der Aa, 1997), but thorough studies have only been made on Psilocybe merdaria (Watling, 1971; Reijnders, 1977), Agaricus bisporus (Worsdell, 1915; Atkins, 1950; Reijnders, 1977; Flegg and Wood, 1985) and Volvariella bombycina (Chiu et al., 1989).

The developmental variants reported include sterile fruit bodies (carpophoroids), forked fruit bodies (where a single stem carries two or more caps), additional secondary caps arising from the cap tissues (= proliferation), bundles of joined basidiomes (= fasciation), and fruit bodies bearing supernumerary hymenia on the upper surface of the pileus.

In Volvariella bombycina, these teratological forms arose spontaneously in two different strains and were found in cultures bearing normal fruit bodies, regardless of the composition of the substrate. Importantly, all hymenia in these forms were functional in the sense that they produced apparently normal basidiospores. The function of the plasticity in fruiting morphogenesis seems to be to maximize spore production and favor dispersal of spores, even under environmental stress. The spore production pathway can tolerate major errors in other parts of the developmental process.

Tropic responses can be considered, quite reasonably, to be an aspect of epigenetic plasticity. Tropisms involve directed growth. Their study is consequently relevant to developmental biology because they can show how particular shapes can arise and how growth can be regulated by varying the expression of the genotype. More importantly, tropisms allow experimental study of these developmental processes. The tropic signal can be repeated as often as needed to accumulate statistically valid observations. Equally, the tropic signal can be attenuated or amplified to study the sensitivity of perception and reaction, and the experiment can be adapted to any observational technique.

Hymenomycete mushroom fruit bodies (polypore and agaric) exhibit a number of tropisms, of which anemotropism, gravitropism, phototropism, and thigmotropism have been clearly demonstrated (Moore, 1991, 1996). At any one time, one tropism usually predominates, but the inferior tropisms can be demonstrated, and during the course of development of a fruit body different tropisms predominate at different times. Gravitropism is the easiest of these to work with. The gravitational field is all pervasive and penetrates everything, so detailed growth experiments can be done with the experimental tissue without damage (Moore et al., 1996).

The stem of Coprinopsis cinereus became gravireceptive after completion of meiosis, implying either some communication between cap and stem or a synchronized timing mechanism (Kher et al., 1992). Stem bending began within 30 minutes of being placed horizontal, although experiments with clinostats showed that the minimum time of stimulation required to elicit a gravitropic reaction was 9.6 min (Hatton and Moore, 1992, 1994). Removal of large segments of the apical part of the stem of Coprinopsis cinereus (extending to about half its length) did not diminish the ability of the stem to show gravitropic bending, but response time was directly proportional to the amount of stem removed, which might imply that the apex produces a morphogenetic signal needed for the bending process. 
Mechanical stress is unlikely to contribute to gravitropic bending because application of lateral loads of up to $20 \mathrm{~g}$ had no adverse effects on adjustment of the stem to the vertical (Greening et al., 1993). In both Flammulina and Coprinopsis, gravity perception seems to be dependent on the actin cytoskeleton because cytochalasin treatment suppresses gravitropic curvature in Flammulina, and in Coprinus significantly delays curvature without affecting stem extension. This, together with altered nuclear motility observed in living hyphae during reorientation, suggests that gravity perception involves statoliths (probably nuclei) acting on the actin cytoskeleton and triggering specific vesicle/ microvacuole release from the endomembrane system (Moore et al., 1996).

Stem bending in Coprinopsis cinereus results from differential enhancement of growth rate in the cells in the outer flank of the bend. There were no significant differences in hyphal diameter, distribution, or populations of cell types, but cells of the outer flank were 4-5 times longer than those of the inner. Thus tropic bending requires only an increase in length of preexisting hyphal cells in the outer flank tissue (Greening et al., 1997). An interesting observation is that large voids, up to $85 \mu \mathrm{m}$ in diameter, occurred only in bent stems. It is thought that such voids may prevent the propagation of cracks through the stem tissue during bending (Greening et al., 1997). Their occurrence, however, shows that the gravitropic morphogenetic program is rather more complex than simply arranging that cells at the bottom grow more rapidly than those at the top. In itself, that may be difficult enough to arrange, but in addition the program includes features that preserve the structural integrity of the tissue as the stresses to which it is subjected change drastically (Moore et al., 2000).

\section{Developmental Subroutines}

Basidiome developmental variants can be used to comment on the ontogenetic program. Because they are actually or potentially functional as basidiospore production and dispersal structures, they have been interpreted as indicating that normal fruit body development comprises a sequence of independent but coordinated morphogenetic subroutines, each of which can be activated or repressed as a complete entity (Moore, 1988, 1998; Chiu et al., 1989; Watling and Moore, 1994; Moore et al., 1998).

For example, there is a "hymenium subroutine" that, in an agaric, is normally invoked to form the "epidermal" layer of the hymenophore (gill lamella); but if it is invoked aberrantly on the upper surface of the cap, it forms not a chaotic travesty of a hymenium but a functional proliferated hymenium. Similarly, the "hymenophore subroutine" produces the classic agaric form when invoked on the lower surface of the pileus, but if wrongly invoked on the upper surface, it produces not a tumorous growth but a recognizable inverted cap.

Normal development of fungal structures in general is thought to depend upon organized execution of such subroutines. The sequence and location in which they are invoked determines the normal developmental pattern (ontogeny) and normal morphology of the fruiting structure. Invocation of these developmental subroutines may be logically equivalent to the "code switches" between different mycelial states discussed by Gregory (1984) and Rayner and Coates (1987). Some of the subroutines can be identified with specific structures, such as basal bulb, stem, cap, hymenophore, hymenium, and veil, but others are rather subtle, affecting positional or mechanical morphogenetic features. One such might be a "grow to enclose" capability, possibly associated primarily with the veil subroutine but perhaps expressed in the stipe base to generate so-called "pilangiocarpic" basidiomes.

Essentially the same subroutines could give rise to morphologically very different forms, depending on other circumstances. For example, the agaric gill hymenophore subroutine seems to be expressed with the rule "where there is space, make gill" (Chiu and Moore, 1990a,b). When this is combined with mechanical anchorages the contortions initially produced by this rule are removed as the gills are stretched along the lines of mechanical stress when the fruit body expands during maturation (Moore, 1998). It is this mechanical process that produces the final morphology. 


\section{Regional Patterns and Commitment}

Fungi, like animals and plants, have a basic "body plan," which is established very early in development. Tissues are demarcated in even the earliest fruit body initials. The processes of regional specification, cell differentiation, and cell coordination essentially establish the pattern sequentially. It is likely that all of these are orchestrated by morphogens and/or growth factors, although there is no direct evidence for the existence of morphogens in the differentiating fruit body primordium.

However, the distributions of cystidia and gills in Coprinus cinereus have been interpreted as being dependent on the interplay between activating and inhibiting "morphogen" factors (Horner and Moore, 1987; Moore, 1988) in a pattern-forming process similar to the model developed by Meinhardt and Gierer $(1974,1980)$ and Meinhardt $(1984,1998)$. Successful application of this morphogenetic field model to fungi as well as to plants and animals concentrates attention on the fact that the distribution of stomata on a leaf, bristles on an insect, and cystidia on a fungal hymenium have a great deal in common at a fundamental mechanistic level. In other words, these examples are expressions of general rules of pattern formation that will apply similarly to all multicellular systems.

Other similarities emerge when a search for commitment is made. The classic demonstration of commitment used in animal embryology involves transplanting a cell into a new environment. If the transplanted cell continues the developmental pathway characteristic of its origin, then it is said to have been committed prior to transplantation. On the other hand, if the transplanted cell embarks upon the pathway appropriate to its new environment, then it was clearly not committed at the time of transplant. Most fungal tissues produce vegetative hyphae very rapidly when disturbed and "transplanted" to a new "environment" or medium. This is a regenerative phenomenon that itself creates the impression that fungal cells express little commitment to their state of differentiation.

Very little formal transplantation experimentation has been reported with fungal multicellular structures. The clearest examples of commitment to a developmental pathway has been provided by Bastouill-Descollonges and Manachère (1984) and Chiu and Moore (1988), who demonstrated that basidia of isolated gills of Coprinus congregatus and Coprinopsis cinereus, respectively, continued development to spore production if removed to agar medium at early meiotic stages. Other hymenial cells, cystidia, paraphyses, and tramal cells immediately reverted to hyphal growth, but this did not often happen to immature basidia. Evidently, basidia are specified irreversibly as meiocytes, and they become determined to complete the sporulation program during meiotic prophase I. Once initiated, the maturation of basidia is an autonomous, endotrophic process that is able to proceed in vitro.

Clearly, then, these experiments demonstrate commitment to the basidium differentiation pathway some time before the differentiated phenotype arises in these fungi. It is also important to stress that other cells of the hymenium do not show commitment. Rather, they immediately revert to hyphal growth on explantation as though they have an extremely tenuous grasp on their state of differentiation. That these cells do not default to hyphal growth in situ implies that some aspect of the environment of the tissue that they normally inhabit somehow continually reinforces their state of differentiation. These uncommitted cells must be considered to be totipotent stem cells. It is this uncommitted state of differentiation of most of the cells in mushroom fruit bodies that accounts for the readiness of field-collected mushrooms to revert to vegetative growth when fragments are inoculated to culture medium.

Mycologists expect as a matter of common routine to be able to make cultures in this way, using the simplest media, from fruit bodies they collect. No animal or plant ecologist can expect to be able to do this. The difference denotes a significant quality of fungal cell differentiation.

\section{Cell Form, Function, and Lineage}

In the hymenium of Agaricus the "epidermal pavement" that provides the structural support for basidia is made up of basidioles (= young basidia) in an ar- 
rested meiotic state. Even after many days' existence, when the fruit body is close to senescence, $30-70 \%$ of the basidioles were in meiotic prophase (Allen et al., 1992). This is not wastage of reproductive potential but use of one differentiation pathway to serve two distinct but essential functions.

Coprinus (as Coprinopsis) illustrates the other extreme by using a highly differentiated cell type, which is called a "paraphysis," to construct the epidermal pavement. These cells arise after the numerically static basidiole population commits to meiosis. Paraphyses arise as branches from beneath the basidia and force their way into the hymenium (Rosin and Moore, 1985). At maturity, individual basidia are surrounded by about five paraphyses; thus, more than $80 \%$ of the hymenial cells in Coprinus serve a structural function. Agaricus and Coprinus hymenophore tissues reach essentially the same structural composition by radically different routes.

Other cell lineages reach the same final morphology through different routes. Both Coprinus cinereus and Volvariella bombycina have facial (pleuro-) and marginal (cheilo-) cystidia. Both types of cystidium in $V$.bombycina are established when the hymenium is first laid down on the folded gills, and, apart from location, their differentiation states and ontogeny appear to be identical. Facial cystidia in Coprinus cinereus are also established as components of the very first population of dikaryotic hyphal tips, which form hymenial tissue and are mostly binucleate as a result (Rosin and Moore, 1985; Horner and Moore, 1987). Marginal cystidia in C. cinereus are the apical cells of branches from the multinucleate gill trama, which become swollen to repair the injury caused when primary gills pull away from the stipe; marginal cystidia retain the multinucleate character of their parental hyphae (Chiu and Moore, 1993).

The "decisions" made during development between different pathways seem to be made with a degree of uncertainty, as though they are based on probabilities rather than absolutes. For example, facial cystidia of $C$. cinereus are generally binucleate, reflecting their origin and the fact that they are sterile cells, yet occasional examples can be found of cystidia in which karyogamy has occurred or of cystidia bearing the sterigmata usually found only on basidia (Chiu and Moore, 1993). This suggests that entry to the cystidial pathway of differentiation does not totally preclude expression of at least part of the differentiation pathway characteristic of the basidium. Equally, the fact that a large fraction of the basidiole population of Agaricus bisporus remains in arrested meiosis indicates that entry to the meiotic division pathway does not guarantee sporulation (Allen et al., 1992). There are many other examples in the literature.

These many examples suggest that fungal cells behave as though they assume a differentiation state even when all conditions for that state have not been met. Rather than rigidly following a prescribed sequence of steps, differentiation pathways in fungal fruit bodies generally appear to be based on application of rules that allow considerable latitude in expression. It is another aspect of the tolerance of imprecision referred to above (Moore et al., 1998). It has been described as a system showing operation of "fuzzy logic" (Moore, 1998), an extension of conventional (Boolean) logic that can handle the concept of partial truth, that is truth values between "completely true" and "completely false." It is the logic underlying modes of decision making that are approximate rather than exact, being able to handle uncertainty and vagueness and has been applied to a wide variety of problems. Decision making in the real world is characterized by the need to process incomplete, imprecise, vague or uncertain information-the sort of information provided by errorprone sensors, inadequate feedback caused by losses in transmission, excessive noise, etc. The importance of fuzzy logic derives from the fact that the theory provides a mathematical basis for understanding how decision making seems to operate generally in nature (Zadeh, 1996; Leondes, 1999).

\section{Degeneration, Senescence, and Death}

In the other two major eukaryotic Kingdoms it is clear that death is an important aspect of biology. Removal of old individuals makes way for the young and allows populations to evolve, and in recent years programmed cell death (PCD) has been recognized as a crucial contributor to morphogenesis in both animals and plants. 
PCD is the removal of tissue in a manner controlled in time and position. There are two types of cell death: traumatic or necrotic death and apoptosis or programmed cell death. In higher animals, PCD involves a sequence of well-regulated processes, including synthetic ones, which lead to internal cell degeneration and eventual removal of the dying cell by phagocytosis. It is important that apoptotic elimination of cells is intracellular in higher animals to avoid escape of antigens and the consequent danger of an immune response to components of the animal's own cells (autoimmunity). This is not a consideration in plants and fungi. The most obvious example of fungal PCD is the autolysis that occurs in the later stages of development of fruit bodies of many species of Coprinus, which Buller $(1924,1931)$ interpreted as an integral part of fruit body development (autolysis removes gill tissue from the bottom of the cap to avoid interference with spore discharge from regions above). Autolysis involves production and organized release of a range of lytic enzymes (Iten, 1970; Iten and Matile, 1970), so autolytic destruction of these tissues is clearly a programmed cell death.

Umar and Van Griensven (1997b, 1998) have found that cell death is a common occurrence in various structures starting to differentiate-for example, the formation of gill cavities in Agaricus bisporus. The authors emphasize that specific timing and positioning definitely imply that cell death is part of the differentiation process. Fungal PCD could play a role at many stages in development of many species (Umar and van Griensven, 1998). In several examples detailed by these authors, the program leading to cell death involves the sacrificed cells overproducing mucilaginous materials, which are then released by cell lysis. In autolysing Coprinus gills, the cell contents released on death contain heightened activities of lytic enzymes. Evidently, in fungal PCD, the cell contents released when the sacrificed cells die could be specialized to particular functions as well. Individual hyphal compartments can be sacrificed to trim hyphae to create particular tissue shaping. It seems, therefore, that PCD in fungi is used to sculpture the shape of the fruit body from the raw medium provided by the hyphal mass of the fruit body initial and primordium.
Only one experimental study of fungal fruit body longevity has appeared. Umar and Van Griensven (1997a) grew the cultivated mushroom in artificial environments that protected the culture from pests and diseases, and under these conditions they found that the life span of fruit bodies of Agaricus bisporus was 36 days. Aging was first evident in fruit bodies about 18 days old, when localized nuclear and cytoplasmic lysis was seen. Remnants of lysed cells aggregated around and between the remaining hyphal cells. Eventually, most of the stem hyphae became empty cylinders, although other cells within the fruit body collapsed irregularly. Electron microscopy of specimens 36 days old and older showed most of the cells in the fruit body to be severely degenerated and malformed. Nevertheless, a number of basidia and subhymenial cells were alive and cytologically intact even on day 36.

Post-harvest physiology and morphology of mushrooms is a prime marketing concern and has been extensively studied. Post-harvest behavior is usually described as senescence or as an aging process, but Umar and Van Griensven (1997a) emphasize that the morphological changes that occur in naturally senescent and post-harvest fruit bodies of $A$. bisporus are different. The harvested mushroom has suffered a traumatic injury, and its post-harvest behavior derives from that. In harvested $A$. bisporus fruit bodies (stored under various conditions), diffuse cell wall damage was observed first and was only later accompanied by cytoplasmic degeneration. A major factor must be inability to replace water lost by evaporation. Exposed surfaces become desiccated and are damaged first. Thus, in what might be called a "post-harvest stress disorder," further damage is inflicted on the cell inwards, from the outside.

In complete contrast, during the senescence that accompanies normal aging, the damage starts inside the cell and proceeds outwards. The nuclear and organelle genomes suffer first, then cytoplasmic integrity, and finally cell wall damage occurs as an aspect of the eventual necrosis suffered as the cell undergoes lysis.

Even in severely senescent fruit bodies Umar and Van Griensven (1997a) found healthy, living cells, and these are presumably the source of origin of an unusual phenomenon known as "renewed fruiting." 
Field-collected fruit body tissues of a mushroom usually generate abundant vegetative hyphae when inoculated onto nutrient agar plates. But there appears to be some sort of "memory" of the differentiated state in these vegetative cells. Initial hyphal outgrowth from gill lamellae usually at first mimics the densely packed branching and intertwined hyphal pattern of the gill tissues from which it is emerging, and is quite unlike the pattern of normal vegetative hyphae in culture. The idea of some sort of memory is not necessarily very exotic in cell biological terms. It need be no more than the residual expression of differentiation-specific genes (such as the hydrophobins, Wessels, 1994a,b, 1996) before their products are diluted out by continued vegetative growth.

Renewed fruiting, though, is more than just a different vegetative mycelium. Entirely new crops of fruit bodies may appear on the remains of the old. Formation of fruit bodies directly on fruiting tissue is not uncommon, and it can occur at various locations (cap, stem, and/or gills) in improperly stored excised fruit bodies. Experiments in vitro show that numerous primordia can arise on excised fruit body tissues and can mature into normal, although miniature, fruit bodies. In comparison to vegetative cultures, the excised fruit body tissues form fruit bodies very rapidly. For example, in Coprinopsis cinereus, renewed fruiting occurred within 4 days, compared with 10-14 days for cultures inoculated with vegetative dikaryon (Chiu and Moore, 1988; Brunt and Moore, 1989).

Renewed fruiting may have an important role in survival, consuming and immediately recycling the resource in the dying fruit body tissue to disperse further crops of spores. For experimentalists it may be more important that renewed fruiting provides an excellent experimental system for the study of fruit body morphogenesis (Bourne et al., 1996), especially for bioassay of fruiting modulators such as heavy metal pollutants like cadmium (Chiu et al., 1998).

\section{PRINCIPLES OF MUSHROOM DEVELOPMENT}

In many fungi hyphae differentiate from the vegetative form that ordinarily composes a mycelium and aggregate to form tissues of multihyphal structures. These may be linear organs (that emphasize parallel arrangements of hyphae) such as strands, rhizomorphs, and fruit body stems; or globose masses (that emphasize interweaving of hyphae) such as sclerotia, fruit bodies, and other sporulating structures of the larger Ascomycota and Basidiomycota. Fungal morphogenesis depends on a series of principles, most of which differ from both animals and plants.

- Principle 1. The fundamental cell biology of fungi on which development depends is that hyphae extend only at their apex, and cross walls form only at right angles to the long axis of the hypha.

- Principle 2. Fungal morphogenesis depends on the placement of hyphal branches. Increasing the number of growing tips by hyphal branching is the equivalent of cell proliferation in animals and plants. To proliferate, the hypha must branch, and to form an organized tissue, the position of branch emergence and its direction of growth must be controlled.

- Principle 3. The molecular biology of the management of cell-to-cell interactions in fungi is completely different from that found in animals and plants.

- Principle 4. Fungal morphogenetic programs are organized into developmental subroutines, which are integrated collections of genetic information that contribute to individual isolated features of the program. Execution of all the developmental subroutines at the right time and in the right place results in a normal structure.

- Principle 5. Because hyphae grow only at their apex, global change to tropic reactions of all the hyphal tips in a structure is sufficient to generate basic fruit body shapes.

- Principle 6. Over localized spatial scales coordination is achieved by an inducer hypha regulating the behavior of a surrounding knot of hyphae 
and/or branches (these are called Reijnders' hyphal knots).

- Principle 7. The response of tissues to tropic signals and the response of Reijnders' hyphal knots to their inducer hyphae, coupled with the absence of lateral contacts between fungal hyphae analogous to the plasmodesmata, gap junctions and cell processes that interconnect neighbouring cells in plant and animal tissues suggest that development in fungi is regulated by morphogens communicated mainly through the extracellular environment.

- Principle 8. Fungi can show extremes of cell differentiation in adjacent hyphal compartments even when pores in the cross wall appear to be open (as judged by transmission electron microscopy).

- Principle 9. Meiocytes appear to be the only hyphal cells that become committed to their developmental fate. Other highly differentiated cells retain totipotency - the ability to generate vegetative hyphal tips that grow out of the differentiated cell to reestablish a vegetative mycelium.

- Principle 10. In arriving at a morphogenetic structure and/or a state of differentiation, fungi are tolerant of considerable imprecision $\left(=\mathrm{ex}^{-}\right.$ pression of fuzzy logic), which results in even the most abnormal fruit bodies (caused by errors in execution of the developmental subroutines) still being able to distribute viable spores, and poorly (or wrongly-) differentiated cells still serving a useful function.

- Principle 11. Mechanical interactions influence the form and shape of the whole fruit body as it inflates and matures, and often generate the shape with which we are most familiar.

\section{REFERENCES}

Allen J. J., Moore D., and Elliott T. J. 1992. Persistent meiotic arrest in basidia of Agaricus bisporus. Mycol Res, 96, 125-127.

Andrews J. H. 1995. Fungi and the evolution of growth form. Can J Bot, 73, S1206-S1212.

Anon. 2003a. Coprinus cinereus sequencing project (http://www.broad.mit.edu). Centre for Genome Research.

Anon. 2003b. Ustilago maydis sequencing project (http: //www.broad.mit.edu. Centre for Genome Research.

Anon. 2003c. Aspergillus sequencing project (http: //www.broad.mit.edu). Centre for Genome Research.

Atkins F. C. 1950. Mushroom Growing Today. London, Faber \& Faber.

Baldauf S. L. and Palmer J. D. 1993. Animals and fungi are each other's closest relatives: Congruent evidence from multiple proteins. Proc Nat Acad Sci USA, 90, 11558-11562.

Baldauf S. L. 1999. A search for the origins of animals and fungi: comparing and combining molecular data. Amer Nat, 154 (suppl.), S178-S188.
Bartnicki-Garcia S. 2002. Hyphal tip growth: outstanding questions. In: Molecular Biology of Fungal Development. H. D. Osiewacz, ed. New York, Marcel Dekker. pp. 29-58.

Bas C. 1969. Morphology and subdivision of Amanita and a monograph of its section Lepidella. Persoonia, 5, 285-579.

Bastouill-Descollonges Y. and Manachère G. 1984. Photosporogenesis of Coprinus congregatus: correlations between the physiological age of lamellae and the development of their potential for renewed fruiting. Physiol Plant, 61, 607-610.

Berbee M. L. and Taylor J. W. 1993. Dating the evolutionary radiations of the true fungi. Can J Bot, 71, 1114-1127.

Berbee M. L. and Taylor J. W. 1999. Fungal phylogeny. In Molecular Fungal Biology. R. P. Oliver and M. Schweizer, eds. Cambridge, UK, Cambridge University Press, pp. 21-77.

Blattny C., Kasala B., Pilt A., Sentilliova-Svobodov J., and Semerdzieva M. 1971. Proliferation of Armillaria mellea (Vahlin Fl. Dan. ex Fr.) P. Karst. probably caused by a virus. Ceska Mykol, 25, 66-74.

Blattny C., Kralik O., Veselsky J., Kasala B., and Herzova H. 1973. Particles resembling virions accompany- 
ing the proliferation of agaric mushrooms. Ceska Mykol, 27, 1-5.

Blelloch R., Newman C., and Kimble J. 1999. Control of cell migration during Caenorbabditis elegans development. Curr Opinion Cell Biol, 11, 608-613.

Bond T. E. T. 1952. A further note on size and form in agarics. Trans Br Mycol Soc, 35, 190-194.

Bondartseva M. A. 1963. On the anatomical criterion in the taxonomy of Aphyllophorales. Bot Z SSSR, $48,362-372$.

Boulianne R. P., Liu Y., Kües U., Lu B. C., and Aebi M. 2000. Fruitbody development in Coprinus cinereus: regulated expression of two galectins secreted by a non-classical pathway. Microbiology, 146, 1841-1853.

Bourne A. M., Chiu S. W., and Moore D. 1996. Experimental approaches to the study of pattern formation in Coprinus cinereus. In: Patterns in Fungal Development. S. W. Chiu and D. Moore, eds. Cambridge, UK, Cambridge University Press. pp. $126-155$.

Brown A.J. and Casselton L. A. 2001. Mating in mushrooms: increasing the chances but prolonging the affair. TIG, 17, 393-400.

Brunt I. C. and Moore D. 1989. Intracellular glycogen stimulates fruiting in Coprinus cinereus. Mycol Res, 93, 543-546.

Buller A. H. R. 1922. Researches on Fungi, vol. 2. London, Longman Green.

Buller A. H. R. 1924. Researches on Fungi, vol. 3. London, Longmans Green.

Buller A. H. R. 1931. Researches on Fungi, vol. 4. London, Longman, Green.

Casselton L. A. and Olesnicky N. S. 1998. Molecular genetics of mating recognition in basidiomycete fungi. Microbiol Mol Biol Rev, 62, 55-70.

Cavalier-Smith T. 1981. Eukaryote Kingdoms: seven or nine? BioSystems, 14, 461-481.

Cavalier-Smith T.1987. The origin of Fungi and pseudofungi. In: Evolutionary Biology of the Fungi. A. D. M. Rayner, C. M. Brasier, and D. Moore, eds. Cambridge, UK, Cambridge University Press. pp. 339-353.

Cavalier-Smith T. 1993. Kingdom Protozoa and its 18 phyla. Microbiol Rev, 57, 953-994.

Cavalier-Smith T. 2002. The phagotrophic origin of eukaryotes and phylogenetic classification of protozoa. Int J Syst Evol Microbiol, 52, 297-354.

Cavalier-Smith T. and Chao E. E. 1995. The opalozoan Apusomonas is related to the common ancestor of animals, fungi and choanoflagellates. Proc Roy Soc Ser B, 261, 1-6.

Chang S.T. and Yau C. K. 1971. Volvariella volvacea and its life history. Amer J Bot, 58, 552-561.

Chiu S. W. and Chang S. T. 1987. Volvariella bombycina and its life history. Mushr J Tropics, 7, 1-12.

Chiu S. W. and Moore D. 1988. Evidence for developmental commitment in the differentiating fruit body of Coprinus cinereus. Trans Br Mycol Soc, 90, 247-253.

Chiu S. W., Moore D., and Chang S. T. 1989. Basidiome polymorphism in Volvariella bombycina. Mycol Res, 92, 69-77.

Chiu S. W. and Moore D. 1990a. A mechanism for gill pattern formation in Coprinus cinereus. Mycol Res, 94, 320-326.

Chiu S. W. and Moore D. 1990b. Development of the basidiome of Volvariella bombycina. Mycol Res, 94, 327-337.

Chiu S. W. and Moore D. 1993. Cell form, function and lineage in the hymenia of Coprinus cinereus and Volvariella bombycina. Mycol Res, 97, 221-226.

Chiu S. W., Chan Y. H., Law S. C., Cheung K. T., and Moore D.1998. Cadmium and manganese in contrast to calcium reduce yield and nutritional value of the edible mushroom Pleurotus pulmonarius. Mycol Res, 102, 449-457.

Chiu S. W. and Moore D. 1999. Sexual development of higher fungi. In: Molecular Fungal Biology. R. P. Oliver and M. Schweizer, eds. Cambridge, UK, Cambridge University Press, pp. 231-271.

Clémençon H. 1997. Anatomie der Hymenomyceten. Teufen, Switzerland, Fluck-Wirth. 996 S.

Clémençon H. 2004. Cytology and Plectology of the Hymenomycetes. Berlin, J. Cramer in der Gebrüder Borntraeger Verlagsbuchhandlung. 632

Copeland H. F. 1956. The Classification of Lower Organisms. Palo Alto, California, Pacific Books.

Corner E.J.H.1932a. The fruit-body of Polystictus xanthopus Fr. Ann Bot, 46, 71-111.

Corner E. J. H. 1932b. A Fomes with two systems of hyphae. Trans Br Mycol Soc, 17, 51-81.

Corner E. J. H. 1966. A monograph of cantharelloid fungi. Annals of Botany Memoirs no. 2. Oxford University, London.

De Groot P.W.J., Schaap P.J., Van Griensven L. J. L. D., and Visser J. 1997. Isolation of developmentally regulated genes from the edible mushroom Agaricus bisporus. Microbiology, 143, 1993-2001.

Dickhardt R. 1983. Homokaryosis and fruiting in Agari- 
cus. Abstracts of The Third International Mycological Congress, Tokyo, p. 54.

Doolittle R. F., Feng D. F., Tsang S., Cho G., and Little E.1996. Determining divergence times of the major kingdoms of living organisms with a protein clock. Science, 271, 470-477.

Duband J. L., Rocher S., Chen W.T., Yamada K. M., and Thiery J. P. 1986. Cell adhesion and migration in the early vertebrate embryo: location and possible role of the putative fibronectin receptor complex. J Cell Biol, 102, 160-178.

Elliot T. J. 1985. The genetics and breeding of species of Agaricus. In: The Biology and Technology of the Cultivated Mushroom. P. B. Flegg, D. M. Spencer, and D. A. Wood, eds. Chicester, Wiley. pp. 111-129.

Elliott T. J. 1972. Sex and the single spore. Mushr Sci, $8,11-18$.

Esser K., Stahl U., and Meinhardt F. 1977. Genetic aspects of differentiation in fungi. In Biotechnology and Fungal Differentiation. J. Meyrath, and J. D. Bu'Lock, eds. London, Academic Press. pp. 67-75.

Feofilova E. P.2001. The Kingdom Fungi: heterogeneity of physiological and biochemical properties and relationships with plants, animals, and prokaryotes. Appl Biochem Microbiol, 37, 124-137.

Field C., Li R., and Oegema K. 1999. Cytokinesis in eukaryotes: a mechanistic comparison. Curr Opin Cell Biol, 11, 68-80.

Flegg P. B. 1983. Response of the sporophores of the cultivated mushroom (Agaricus bisporus) to volatile substances. Scientia Hort, 21, 301-310.

Flegg P. B. and Wood D. A. 1985. Growth and fruiting. In: The Biology and Technology of the Cultivated Mushroom. P. B. Flegg, D. M. Spencer, and D. A. Wood, eds. New York, Wiley. pp. 141-177.

Flegg P. B. 1996. The shape and form of mushrooms. Mushr J Trop, 560, 12-13.

Fries E. 1821. Systema Mycologicum, volume I. Mauritius, Gryphiswald.

Galagan J. E., Calvo S. E., Borkovich K. A., et al. 2003. The genome sequence of the filamentous fungus Neurospora crassa. Nature, 422, 859-868.

Gallagher K. and Smith L. G. 1997. Asymmetric cell division and cell fate in plants. Curr Opin Cell Biology, 9, 842-848.

Gancedo J. M. 2001. Control of pseudohyphae formation in Saccharomyces cerevisiae. FEMS Microbiol Rev, 25, 107-123.
Graham K. M. 1985. Mating type of progeny from haploid sporocarps of Pleurotus flabellatus (Berk. et Br.) Sacc. Malaysian Appl Biol, 14, 104-106.

Gray J. 1985. The microfossil record of early land plants: advances in understanding of early terrestrialisation. Pbil Trans Roy Soc, ser B 309, 167-195.

Greening J. P., Holden J., and Moore D. 1993. Distribution of mechanical stress is not involved in regulating stem gravitropism in Coprinus cinereus. Mycol Res, 97, 1001-1004.

Greening J. P., Sánchez C., and Moore D. 1997. Coordinated cell elongation alone drives tropic bending in stems of the mushroom fruit body of Coprinus cinereus. Can J Bot, 75, 1174-1181.

Gregory P. H. 1984. The fungal mycelium-an historical perspective. In: The Ecology and Physiology of the Fungal Mycelium. D. H. Jennings and A. D. M. Rayner, eds. Cambridge, UK, Cambridge University Press, pp. 383-417.

Gupta R. S. and Golding G. B. 1996. The origin of the eukaryotic cell. TBS, 21, 166-171.

Hammad F.,JiJ., Watling R., and Moore D. 1993a. Cell population dynamics in Coprinus cinereus: coordination of cell inflation throughout the maturing fruit body. Mycol Res, 97, 269-274.

Hammad F., Watling R., and Moore D. 1993b. Cell population dynamics in Coprinus cinereus: narrow and inflated hyphae in the basidiome stipe. Mycol Res, 97, 275-282.

Han K. H., Lee D. B., Kim J. H., Kim M. S., Han K. Y., Kim W. S., Park Y. S., Kim H. B., and Han D. M. 2003. Environmental factors affecting development of Aspergillus nidulans. J Microbiol, 41, 34-40.

Harper J. L., Rosen B. R., and White J. 1986. The Growth and Form of Modular Organisms. London, The Royal Society. 250 pp.

Harris S. D. 2001. Septum formation in Aspergillus nidulans. Curr Opinion Microbiol, 4, 736-739.

Harris S. D., Hofmann A. F., Tedford H. W., and Lee M.P. 1999. Identification and characterization of genes required for hyphal morphogenesis in the filamentous fungus Aspergillus nidulans. Genetics, 151, 1015-1025.

Harvey R., Lyon A. G., and Lewis P. N. 1969. A fossil fungus from the Rhynie Chert. Trans Br Mycol Soc, $53,155-156$.

Hass H., Taylor T. N., and Remy W. 1994. Fungi from the Lower Devonian Rhynie Chert-mycoparasitism. Amer J Bot, 81, 29-37. 
Hatton J. P. and Moore D. 1992. Kinetics of stem gravitropism in Coprinus cinereus: determination of presentation time and "dosage-response" relationships using clinostats. FEMS Microbiol Lett, 100, 82-86.

Hatton J. P. and Moore D. 1994. Kinetics of stipe gravitropism in the mushroom fungus Coprinus cinereus under the conditions of microgravity simulation provided by clinostat treatment. Microgravity Quarterly, 4, 101-106.

Heckman D. S., Geiser D. M., Eidell B. R., Stauffer R. L., Kardos N. L., and Hedges S. B. 2001. Molecular evidence for the early colonization of land by fungi and plants. Science, 293, 1129-1133.

Horner J. and Moore D. 1987. Cystidial morphogenetic field in the hymenium of Coprinus cinereus. Trans Br Mycol Soc, 88, 479-488.

Howard R. J. and Gow N. A. R. 2001. The Mycota: Biology of the Fungal Cell. Springer-Verlag, Berlin-Heidelberg-New York, 300 pp.

Hueber F. M. 2001. Rotted wood-alga-fungus: the history and life of Prototaxites Dawson 1859. Rev Palaeobot Palynol, 116, 123-158.

Ingold C. T. 1946. Size and form in agarics. Trans $\mathrm{Br}$ Mycol Soc, 29, 108-113.

Iten W. 1970. Zur funktion hydrolytischer enzyme bei der autolysate von Coprinus. Ber Schweitz Bot Ges, 79, 175-198.

Iten W. and Matile P. 1970. Role of chitinase and other lysosomal enzymes of Coprinus lagopus in the autolysis of fruiting bodies. J Gen Microbiol, 61, 301-309.

Kalgutkar R. M. and Sigler L. 1995. Some fossil fungal form-taxa from the Maastrichtian and Palaeogene ages. Mycol Res, 99, 513-522.

Kamada T. and Takemaru T. 1977a. Stipe elongation during basidiocarp maturation in Coprinus macrorhizus: changes in polysaccharide composition of stipe cell wall during elongation. Pl Cell Physiol, 18, 1291-1300.

Kamada T. and Takemaru T. 1977b. Stipe elongation during basidiocarp maturation in Coprinus macrorbizus: mechanical properties of stipe cell wall. $P l$ Cell Physiol, 18, 831-840.

Kanda T. and Ishikawa T. 1986. Isolation of recessive developmental mutants in Coprinus cinereus.J Gen Appl Microbiol, 32, 541-543.

Kanda T., Goto A., Sawa K., Arakawa H., Yasuda Y., and Takemaru T. 1989. Isolation and characterization of recessive sporeless mutants in the basidiomycete Coprinus cinereus. Mol Gen Genet, 216, 526-529.

Kanda T., Arakawa H., Yasuda Y., and Takemaru T. 1990. Basidiospore formation in a mutant of incompatibility factors and in mutants that arrest at meta-anaphase I in Coprinus cinereus. Exper Mycol, 14, 218-226.

Katz L.A.1998. Changing perspectives on the origin of eukaryotes. Trends Ecol Evol, 13, 493-497.

Katz L. A. 1999. The tangled web: gene genealogies and the origin of eukaryotes. Am Nat, 154 (suppl.), S137-S145.

Keyworth W. G. 1942. The occurrence of tremelloid outgrowths on the pilei of Coprinus ephemerus. Trans Br Mycol Soc, 25, 307-310.

Kher K., Greening J. P., Hatton J. P., Novak Frazer L., and Moore D. 1992. Kinetics and mechanics of stem gravitropism in Coprinus cinereus. Mycol Res, 96, 817-824.

Knoll A. H. 1992. The early evolution of eukaryotes: a geological perspective. Science, 256, 622-627.

Knoll A. H. 2003. Life on a Young Planet: The First Three Billion Years of Evolution on Earth. Princeton, New Jersey, Princeton University Press, 304 pp.

Kothe E. 2002. Sexual development in basidiomycetes. In: Molecular Biology of Fungal Development. H. D. Osiewacz, ed. New York, Marcel Dekker, pp. 245-273.

Kronstad J. W. and Staben C. 1997. Mating type in filamentous fungi. Ann Rev Genet, 31, 245-276.

Kües U. and Casselton L. A. 1992. Fungal mating type genes-regulators of sexual development. Mycol Res, 96, 993-1006.

Kües U., Granado J. D., Hermann R., Boulianne R. P., Kertesz-Chaloupková, and Aebi M. 1998. The $A$ mating type and blue light regulate all known differentiation processes in the basidiomycete Coprinus cinereus. Mol Gen Genet, 260, 81-91.

Kües U. 2000. Life history and developmental processes in the basidiomycete Coprinus cinereus. Microbiol Mol Biol Rev, 64, 316-353.

Kües U. and Liu Y. 2000. Fruiting body production in basidiomycetes. Appl Microbiol Biotech, 54, 141-152.

Kües U., Polak E., Bottoli A. P. F., Hollenstein M., Walser P. J., Boulianne R. P., Hermann R., and Aebi M. 2002. Vegetative development in Coprinus cinereus. In: Molecular Biology of Fungal Development. H. D. Osiewacz, ed. New York, Marcel Dekker, pp. 133-163. 
Kuma K., Nikoh N., Iwabe N., and Miyata T. 1995. Phylogenetic position of Dictyostelium inferred from multiple protein data sets. $J$ Mol Evol, 41, 238-246.

Kumar S. and Rzhetsky A. 1996. Evolutionary relationships of eukaryotic kingdoms. J Mol Evol, 42, 183-193.

Lambert E. B. 1930. Two new diseases of cultivated mushrooms. Phytopathol, 20, 917-919.

Leatham G. F. and Stahmann M. N. 1987. Effect of light and aeration on fruiting of Lentinula edodes. Trans Br Mycol Soc, 88, 9-20.

Leondes C.T. 1999. Fuzzy Theory Systems: Techniques and Applications. New York, Academic Press,

Leslie J. F. and Leonard T. J. 1979. Three independent genetic systems that control initiation of a fungal fruiting body. Mol Gen Genet, 171, 257-260.

Leslie J. F. and Leonard T. J. 1984. Nuclear control of monokaryotic fruiting in Schizophyllum commune. Mycologia, 76, 760-763.

Lu B. C., Gallo N., and Kües U. 2003. White-cap mutants and meiotic apoptosis in the basidiomycete Coprinus cinereus. Fungal Genet Biol, 39, 82-93.

Manachère G., Robert J. C., Durand R., Bret J. P., and Fevre M. 1983. Differentiation in the Basidiomycetes. In: Fungal Differentiation: a Contemporary Synthesis. J. E. Smith, ed. New York, Marcel Dekker, pp.481-514.

Manachère G. 1985. Sporophore differentiation of higher fungi: a survey of some actual problems. Physiol Vég, 23, 221-230.

Manachère G. 1988. Regulation of sporophore differentiation in some macromycetes, particularly in coprini: an overview of some experimental studies, from fruiting initiation to sporogenesis. Crypt Mycol, 9, 291-323.

Margulis L. 1974. Five-Kingdom classification and the origin and evolution of cells. Evol Biol, 7, 45-78.

Margulis L. 1992. Biodiversity-molecular biological domains, symbiosis and Kingdom origins. BioSystems, 27, 39-51.

Margulis L. 2004. Serial endosymbiotic theory (SET) and composite individuality: transition from bacterial to eukaryotic genomes. Microbiol Today, 31, 172-174.

Margulis L. and Schwartz K. V. 1982. Five Kingdoms: An Illustrated Guide to the Phyla of Life on Earth. San Francisco: Freeman.

Meinhardt F. and Esser K. 1983. Genetic aspects of sexual differentiation in fungi. In: Fungal Dif- ferentiation. J. E. Smith, ed. New York, Marcel Dekker, pp. 537-557.

Meinhardt H. and Gierer A. 1974. Applications of a theory of biological pattern formation based on lateral inhibition. J Cell Sci, 15, 321-346.

Meinhardt H. and Gierer A. 1980. Generation and regeneration of sequence of structures during morphogenesis. J Theoret Biol, 85, 429-450.

Meinhardt H. 1984. Models of pattern formation and their application to plant development. In: Positional Controls in Plant Development. P. W. Barlow and D. J. Carr, eds. Cambridge, UK, Cambridge University Press, pp. 1-32.

Meinhardt H. 1998. The Algorithmic Beauty of Sea Shells. New York-Heidelberg-Berlin, SpringerVerlag, 236 pp.

Meškauskas A., Fricker M. D., and Moore D. 2004a. Simulating colonial growth of fungi with the Neighbour-Sensing model of hyphal growth. Mycol Res, 108, 1241-1256.

Meškauskas A., McNulty L. J., and Moore D. 2004b. Concerted regulation of all hyphal tips generates fungal fruit body structures: experiments with computer visualisations produced by a new mathematical model of hyphal growth. Mycol Res, 108, 341-353.

Meškauskas A. 2005. Using web agents for data mining of fungal genomes. In: Applied Mycology and Biotechnology, Vol 6, Genes, Genomics and Bioinformatics. D. K. Arora and R. Berka, eds. Elsevier Science. In press.

Meyerowitz E. M. 1999. Plants, animals and the logic of development. Trends Cell Biol, 9, M65-M68.

Molina R., Pilz D., Smith J., Dunham S., Dreisbach T., O'Dell T., and Castellano M. 2001. Conservation and management of forest fungi in the Pacific Northwestern United States: an integrated ecosystem approach. In: Fungal Conservation: Issues and Solutions. D. Moore, M. M. Nauta, S. E. Evans, and M. Rotheroe, eds. Cambridge, UK, Cambridge University Press, pp. 19-63.

Momany M. 2001. Cell biology of the duplication cycle in fungi. In: Molecular and Cellular Biology of Filamentous Fungi. N. J. Talbot, ed. Oxford, UK, Oxford University Press, pp. 119-125.

Momany M. 2002. Polarity in filamentous fungi: establishment, maintenance and new axes. Curr Opinion Microbiol, 5, 580-585.

Momany M., Zhao J., Lindsey R., and Westfall P. J. 2001. Characterization of the Aspergillus ni- 
dulans septin (asp) gene family. Genetics, 157, 969-977.

Moore D. 1981. Developmental genetics of Coprinus cinereus: genetic evidence that carpophores and sclerotia share a common pathway of initiation. Curr Genet, 3, 145-150.

Moore D.1988. Recent developments in morphogenetic studies of higher fungi. Mushr J Trop, 8, 109-128.

Moore D. 1991. Perception and response to gravity in higher fungi-a critical appraisal. New Phytol, 117, 3-23.

Moore D. 1996. Graviresponses in fungi. Adv Space Res, $17,73-82$.

Moore D. 1998. Fungal Morphogenesis. New York, Cambridge University Press, 469 pp.

Moore D., Chiu S. W., Umar M. H., and Sánchez C. 1998. In the midst of death we are in life: further advances in the study of higher fungi. Bot $J$ Scotland, 50, 121-135.

Moore D., Hock B., Greening J. P., Kern V. D., Novak Frazer L., and Monzer J. 1996. Gravimorphogenesis in agarics. Mycol Res, 100, 257-273.

Moore D., Meškauskas A., Reeve M. A., Sánchez C., and Chiu S. W. 2000. Mushroom mechanics and mathematical models of mushroom morphogenesis. In: Science and Cultivation of Edible Fungi. L. J. L. D. Van Griensven, ed. Rotterdam, Balkema, pp. 103-107.

Moore D., Walsh C., and Robson G. D. 2005. A search for developmental gene sequences in the genomes of filamentous fungi. In: Applied Mycology and Biotechnology, Vol 6, Genes, Genomics and Bioinformatics. D. K. Arora and R. Berka, eds. Elsevier Science. In press.

Mösch H.-U. 2002. Pseudohyphal growth in yeast. In: Molecular Biology of Fungal Development. $\mathrm{H}$. D. Osiewacz, ed. New York, Marcel Dekker, pp. $1-21$.

Muller-Dieckmann H. J., Grantz A. A., and Kim S. H. 1999. The structure of the signal receiver domain of the Arabidopsis thaliana ethylene receptor ETR1. Structure, 7, 1547-1556.

Novak Frazer L. 1996. Control of growth and patterning in the fungal fruiting structure. A case for the involvement of hormones. In: Patterns in Fungal Development. S. W. Chiu and D. Moore, eds. Cambridge, UK, Cambridge University Press, pp. 156-181.

Patterson D.J. 1999. The diversity of eukaryotes. Amer Nat, 154 (suppl.), S96-S124.
Patterson D. J. and Sogin M. L. 2000. Tree of Life web project. http://tolweb.org/tree.

Peabody R. B., Peabody D. C., and Sicard K. M. 2000. A genetic mosaic in the fruiting stage of Armillaria gallica. Fungal Genet Biol, 29, 72-80.

Persoon D. C. H. 1801. Synopsis Methodica Fungorum. Gottingae, Henricum Dieterich.

Philippe H., Germot A., and Moreira D. 2000. The new phylogeny of eukaryotes. Curr Opinion Genet Devel, 10, 596-601.

Pirozynski K. A. 1976a. Fungal spores in fossil record. Biol Memoirs, 1, 104-120.

Pirozynski K. A. 1976b. Fossil fungi. Ann Rev Phytopath, 14, 337-346.

Pirozynski K. A. 1981. Interactions between fungi and plants through the ages. Can J Bot, 59, 1824-1827.

Pöder R. 1992. Phylogenetical aspects of gill development and proportions in basidiocarps. Mycol Helv, 5, 39-46.

Prillinger H. and Six W.1983. Genetische untersuchungen zur fruchtkorper und artbildung bei basidiomyceten: Genetische kontrolle der fruchtkorperbildung bei Polyporus ciliatus. Plant Syst Evol, 141, 341-371.

Raper J. R. and Krongelb G. S. 1958. Genetic and environmental aspects of fruiting in Schizophyllum commune Fr. Mycologia, 50, 707-740.

Raudaskoski M. and Salonen M. 1984. Interrelationships between vegetative development and basidiocarp initiation. In: The Ecology and Physiology of the Fungal Mycelium. D. H. Jennings and A. D. M. Rayner, eds. Cambridge, UK, Cambridge University Press, pp. 291-322.

Rayner A. D. M. and Coates D. 1987. Regulation of mycelial organization and responses. In: Evolutionary Biology of the Fungi. A. D. M. Rayner, C. M. Brasier, and D. Moore, eds. Cambridge, UK, Cambridge University Press, pp. 115-136.

Redhead S. A. 1987. The Xerulaceae (Basidiomycetes), a family with sarcodimitic tissues. Can J Bot, 65, 1551-1562.

Redhead S. A., Vilgalys R., Moncalvo J. M., Johnson J., and Hopple J. S. 2001. Coprinus Pers. and the disposition of Coprinus species sensu lato. Taxon, 50, 203-241.

Reijnders A. F. M. 1948. Etudes sur le développement et l'organization histologique des carpophores dans les Agaricales. Rec Trav bot Neerland, 41, 213-396. 
Reijnders A. F. M. 1963. Les problèmes du développement des carpophores des Agaricales et de quelques groupes voisins. The Hague, Dr W. Junk. 412 pp.

Reijnders A. F. M. 1976. Recherches sur le développement et l'histogenèse dans les Asterérosporales. Persoonia, 9, 65-83.

Reijnders A. F. M. 1977. The histogenesis of bulb and trama tissue of the higher Basidiomycetes and its phylogenetic implications. Persoonia, 9, 329-362.

Reijnders A. F. M. 1993. On the origin of specialised trama types in the Agaricales. Mycol Res, 97, 257-268.

Reijnders A. F. M. 2000. A morphogenetic analysis of the basic characters of the gasteromycetes and their relation to other basidiomycetes. Mycol Res, 104, 900-910.

Reijnders A. F. M. and Stalpers J. A. 1992. The development of the hymenophoral trama in the Aphyllophorales and the Agaricales. In: Studies in Mycology, No 34. Baarn, The Netherlands: Centraalbureau voor Schimmelcultures.

Retallack G. J. 1994. Were the ediacaran fossils lichens? Paleobiology, 20, 523-544.

Roger A. J. 1999. Reconstructing early events in eukaryotic evolution. Amer Nat, 154 (suppl.), S146-S163.

Rosin I. V. and Moore D. 1985. Differentiation of the hymenium in Coprinus cinereus. Trans Br Mycol Soc, $84,621-628$.

Royse D. J., Jodon M. H., Antoun G. G., and May B. P. 1987. Confirmation of intraspecific crossing and single and joint segregation of biochemical loci of Volvariella volvacea. Experiment Mycol, 11, 11-18.

Ryvarden L. 1992. Genera of polypores, nomenclature and taxonomy. Synopsis Fungorum, 5, 363 pp.

Sánchez C. 2004. Influence of the substrate on ultrastructure of Pleurotus pulmonarius fruit body primordia. Appl Microbiol Biotech, 64, 691-694.

Seiler S. and Plamann M. 2003. The genetic basis of cellular morphogenesis in the filamentous fungus Neurospora crassa. Mol Biol Cell, 14, 4352-4364.

Selosse M.-A. 2002. Prototaxites: a 400 Myr old giant fossil, a saprohytic holobasidiomycete or a lichen? Mycol Res, 106, 642-644.

Selosse M.-A. and Le Tacon F. 1998. The land flora: a phototroph-fungus partnership? Trends Ecol Evol, 13, 15-20.

Singer R. 1975. The Agaricales in Modern Taxonomy, 3rd ed. Vaduz, J. Cramer.

Sogin M. L., Morrison H. G., Hinkle G., and Silberman
J. D. 1996. Ancestral relationships of the major eukaryotic lineages. Microbiologia, 12, 17-28.

Sogin M. L. and Silberman J. D. 1998. Evolution of the protists and protistan parasites from the perspective of molecular systematics. Int J Parasitol, 28, $11-20$.

Southwood R. 2003. The Story of Life. Oxford, UK, Oxford University Press, 264 pp.

Stahl U. and Esser K. 1976. Genetics of fruit body production in higher basidiomycetes. I. Monokaryotic fruiting and its correlation with dikaryotic fruiting in Polyporus ciliatus. Mol Gen Genet, 148, 183-197.

Stearns J. C. and Glick B. R. 2003. Transgenic plants with altered ethylene biosynthesis or perception. Biotechnol Adv, 21, 193-210.

Steimer A., Schob H., and Grossniklaus U. 2004. Epigenetic control of plant development: new layers of complexity. Curr Opinion Plant Biol, 7, 11-19.

Sugiyama J. 1998. Relatedness, phylogeny, and evolution of the fungi. Mycoscience, 39, 487-511.

Takemaru T. and Kamada T. 1972. Basidiocarp development in Coprinus macrorbizus. I. Induction of developmental variations. Bot Mag, 85, 51-57.

Taylor T. N., Remy W., Hass H., and Kerp H. 1995. Fossil arbuscular mycorrhizae from the early Devonian. Mycologia, 87, 560-573.

Umar M.H. and Van Griensven L.J. L. D. 1997a. Morphological studies on the life span, developmental stages, senescence and death of Agaricus bisporus. Mycol Res, 101, 1409-1422.

Umar M.H. and Van Griensven L.J. L. D. 1997b. Morphogenetic cell death in developing primordia of Agaricus bisporus. Mycologia, 89, 274-277.

Umar M. H. and van Griensven L. J. L. D. 1998. The role of morphogenetic cell death in the histogenesis of the mycelial cord of Agaricus bisporus and in the development of macrofungi. Mycol Res, 102, 719-735.

Uno I. and Ishikawa T. 1971. Chemical and genetical control of induction of monokaryotic fruiting bodies in Coprinus macrorbizus. Mol Gen Genet, 113, 228-239.

van der Aa H. 1997. Confluent basidiocarps. Mycologist, $11,81$.

van Loon P. C. C., Sonnenberg A. S. M., Swinkels H.A. T. I., van Griensven L. J. L. D., and van der Heijden G.W.A.M.1995. Objective measurement of developmental stage of white button mushrooms (Agaricus bisporus). In: Science and Cultivation of 
Edible Fungi.T.J. Elliott, ed. Rotterdam, Balkema, pp. 703-708.

Wainright P. O., Hinkle G., Sogin M. L., and Stickel S. K. 1993. Monophyletic origin of the Metazoa: an evolutionary link with fungi. Science, 260, 340-342.

Warenda A. J. and Konopka J. B. 2002. Septin function in Candida albicans morphogenesis. Mol Biol Cell, 13, 2732-2746.

Watling R. 1971. Polymorphism in Psilocybe merdaria. New Phytol, 70, 307-326.

Watling R. 1974. Dimorphism in Entoloma abortivum. Bull Soc Linn Lyon, 43, 449-470.

Watling R. 1975. Studies in fruit body development in the Bolbitiaceae and the implications of such work. Nova Hedwigia, 51, 319-346.

Watling R. and Nicoll H. 1980. Sphaerocysts in Lactarius rufus. Trans Br Mycol Soc, 75, 331-333.

Watling R. and Moore D. 1994. Moulding moulds into mushrooms: shape and form in the higher fungi. In: Shape and Form in Plants and Fungi. D. S. Ingram and A. Hudson, eds. London, Academic Press, pp. 270-290.

Wellman C. H. 1995. Phytodebris from Scottish Silurian and Lower Devonian continental deposits. Rev $\mathrm{Pa}$ laeobot Palynol, 84, 255-279.
Wellman C.H. and GrayJ.2000. The microfossil record of early land plants. Phil Trans Roy Soc, ser B 355, 717-732.

Wessels J. G. H. 1994a. Developmental regulation of fungal cell wall formation. Ann Rev Phytopathol, 32, 413-437.

Wessels J. G. H. 1994b. Development of fruit bodies in Homobasidiomycetes. In: The Mycota, Growth, Differentiation and Sexuality. J. G. H. Wessels and F. Meinhardt, eds. Berlin, Heidelberg, New York, Springer-Verlag, pp. 351-366.

WesselsJ.G.H.1996. Fungal hydrophobins: proteins that function at an interface. Trends Plant Sci, 1, 9-15.

Whitaker R. H. 1969. New concepts of kingdoms of organisms. Science, 163, 150-160.

Worsdell W. C.1915. The Principles of Plant Teratology, vol 1. London, The Ray Society.

Wright V. P. 1985. The precursor environment for vascular plant colonization. Phil Trans Roy Soc, ser B 309, 143-145.

Zadeh L.A. 1996. Fuzzy logic $=$ computing with words. IEEE Trans Fuzzy Syst, 4, 103-111.

Zhao X. C., Qu X., Mathews D. E., and Schaller G. E. 2002. Effect of ethylene pathway mutations upon expression of the ethylene receptor ETR1 from Arabidopsis. Plant Physiol, 130, 1983-1991. 